\title{
Amores locos. A propósito de la mania erótica en el Fedro.
}

\author{
Crazy loves. About erotic mania in the Phaedrus
}

\author{
Por: María Angélica Fierro* \\ msmariangelica@gmail.com \\ Instituto de Filosofía-Departamento de Filosofía \\ Facultad de Filosofía y Letras, Universidad de Buenos Aires \\ Consejo Nacional de Investigaciones Científicas y Técnicas \\ ARGENTINA \\ ORCID: 0000-0002-9805-2081
}

Trabajo Recibido: 25/02/2019

Trabajo Aprobado: 6/03/2019

Doi: $10.30972 /$ nvt.0143713

You have everything but one thing: madness.

A man needs a litlle madness or else he never dares to cut the rope and be free.

Nikos Kazantzakis, Zorba the Greek

No estoy muerto. Estoy enamorado. Adolfo Bioy Casares, La invención de Morel

Resumen: En el presente trabajo intentaré mostrar que en el Fedro la mania, en tanto estado alterado de conciencia, representa para Platón desde un síntoma de un máximo desequilibrio psíquico y una corrupción ético-cognitiva hasta un estado mental privilegiado, propio de la locura profética, catártica, poética y, particularmente, de la erótica. En tal sentido mostraré que:

i. En el Primer Discurso de Sócrates (238b-c) la definición de erōs como "apetito connatural por los placeres" e irracional vs. la "opinión adquirida orientada a lo mejor" (equiparada aquí a la sōphrosynē como perfección de la enkrateia), ya

\footnotetext{
* Las traducciones de los textos de Platón son propias según la edición de Burnet (1899-1907). En el resto de los textos griegos mencionados sigo las ediciones del TLG e indico, cuando corresponde, el autor de la traducción. Las abreviaturas de las obras se dan según el LSJ. En el caso de las citas del Fedro refiero a mi traducción realizada para editorial Colihue, Buenos Aires, actualmente en prensa; en los pasajes de este diálogo he omitido la abreviatura y refiero directamente al número. Agradezco especialmente los útiles comentarios de uno de los evaluadores anónimos del presente trabajo.

* Doctora en Filosofía por la Universidad de Durham (Reino Unido). Investigadora Independiente del Consejo Nacional de Investigaciones Científicas y Técnicas (CONICET, Argentina). Docente de Historia de la Filosofía Antigua, Facultad de Filosofía y Letras, Universidad de Buenos Aires (Argentina).
} 
sugerida a través de la descripción del amante en el Discurso lisíaco (230e-234c), presenta la locura erótica como reñida con la razón, en concordancia con la visión del sentido común.

ii. El Segundo Discurso de Sócrates (243e-257c) constituye una instancia superadora a esta alternativa al proponer que: a) tanto en la locura amorosa ordinaria como en la de origen divino existe una exacerbación del apetito (epithymia) sexual en el amante ante la belleza física del amado que causa una percepción y modo de actuar que se aparta de los parámetros normales; b) no obstante, ambas se diferencian en que, mientras en el caso del erōs "izquierdo" (266a) este queda reducido a su expresión apetitiva y se desarrolla sin freno, en el del erōs "derecho" (266a) precisamente la renuncia a la satisfacción sexual no solo impulsa sino que exacerba el amor a la sabiduría, tanto en el amante como en el amado y estimula así en la parte racional del alma el deseo de captación de la belleza en sí.

iii. Finalmente me referiré a cómo en el contexto del mito se presentan tres formas de anamnēsis vinculadas de distinto modo con la locura erótica. Por una parte, el verdadero amante enloquecido de amor por el joven, rememora, gracias a la belleza en él presente y de un modo más o menos consciente, una captación directa y extradiscursiva de un ámbito divino y trascendente. Esta modalidad de la razón sería, no obstante, estimulante a la vez que complementaria -no meramente anticipatoria- a los ineludibles esfuerzos del trabajo dialéctico-argumentativo y reflexivo de la razón, descripta en el mito como reconstrucción rememorativa del entramado eidético. A ello se agrega un tercer tipo de anamnēsis consistente en recordar el tipo de configuración psíquica divina correspondiente a nuestra alma a través de la contemplación de la estructura isomórfica del alma del amado; en el caso de los amantes filósofos, se trataría de un alma "tipo Zeus", que representa el ideal de una cómoda conducción de los aspectos irracionales al estar sustentada en un satisfactorio cumplimiento de los anhelos de la razón.

Palabras claves: amor, locura, reminiscencia, Fedro, Platón 
Abstract: Here I aim to show that in Plato's Phaedrus mania is described as an alterated state of consciousness which equally refers to a sympton of mental disorder and/or ethical-cognitive corruption as well as a privileged state of mind which is the case of prophetic madness, cathartic madness, poetic madness and, especially, erotic madness. Thus I intend to argue in favor to the following theses:

i. In Socrates' First Speech (238b-c) erōs is defined as an irrational, inborn desire for pleasures in beauty vs. acquired opinion which aims at the best (that is to say, sōphrosyne as perfection of self-control or enkrateia), as it had already been anticipated through the portrait of the lover in the Lysiac speech (230e-324c). Thus erotic madness is depicted as opposite to reason in accordance with common sense's view.

ii. Socrates' Second Speecch (243e-257c) overcomes this opposition for the following reasons: a) In both ordinary erotic madness and divine erotic madness exacerbation of fleshly desires takes place insofar as the physical beauty of the beloved one provokes a distorted perception and behaviour from the average parameters of rationality. b) Nevertheless, each kind of erotic mania differs from each other, insofar as "left" erōs is reduced to its appetive manifestation and develops without restraint, while in "right" erōs (266a) renunciation to sexual satisfaction does not only motivate but also increases love of wisdom. Thus reason's yearning for catching sight of beauty itself is estimulated in both the lover and the beloved one.

iii. Finally I will tackle how in the myth of the winged chariot three kinds of anamnēsis are related in different ways to erotic madness. First of all, the true lover who is madly in love with a handsome young lad remembers, thanks to the presence of beauty in the boy and in different degrees of awareness, reason's direct, extradiscursive insight of a divine and trascendent realm (the Forms, especially the Form of Beauty). This kind of recollection enhances -not mereley anticipates- a second kind of anamnesis, that is reason's dialectical efforts to rebuild the map of eidetic reality. Finally there is a third kind of anamnēsis: the lover's recollection of which kind of godlike psychological structure corresponds to his own soul through the sight of the beloved one's soul which is isomorphic to it. In the case of the 
philosopher-lovers they discover their souls are Zeus-like insofar as Zeus stands for the ideal of someone who can handle his irrational aspects without effort thanks to a sustained fulfillment of reason's desire for truth.

Keywords: madness, love, reminescence, Phaedrus, Plato

\section{Cómo citar este artículo:}

APA: Fierro, M. A. (2019). Amores locos. A propósito de la mania erótica en el Fedro. Nuevo Itinerario, 14 (1), 138-174. Recuperado de: (agregar dirección web)

En su Segundo Discurso del Fedro (243e-257b) Sócrates, a fin de ofrecer una retractación de los dos parlamentos previos, censuradores de erōs a causa de sus efectos perjudiciales en el amado pero también en el amante, y de demostrar, en cambio, las bondades que el amor nos depara por ser en realidad un dios, realiza una argumentación basada en una tesis extraordinaria. Esta es que hay cuatro tipos de mania de procedencia divina -diferenciados de acuerdo al método dialéctico de división y reunión a desarrollar luego en la Segunda Parte (265a-266c)-: la profética, la teléstica o catártica, la poética y la erótica, siendo esta última el mejor tipo de locura (243e-245a). Leemos así en 245b:

Así que no temamos justamente eso, ni dejemos que algún discurso nos ofusque al atemorizarnos con que se debe preferir como amigo al que está en su sano juicio (ton sōphrona) antes que al movilizado por la locura (pro tou kekinēmenou). ${ }^{1}$ Sino que solo tras demostrar, además de aquello, esto, que el amor no es enviado por los dioses en provecho del amante y el amado, ese discurso se lleve el premio. Por nuestra parte, nosotros debemos demostrar lo opuesto: que tal locura (mania) es concedida por los dioses (para theōn) para la mejor de las suertes. La demostración, ciertamente, será increíble para los sagaces, pero creíble para los sabios.

${ }^{1}$ Kekinēmenos tiene aquí el sentido de "emocionalmente movilizado". Vid. LSJ s.v. kineō B.2.; también Ryan (2012, ad loc). 
Resulta en verdad sorprendente que la mania, caracterizada en el fragmento de Pródico ("Pues erōs es epithymia duplicado, y erōs duplicado se vuelve mania", DK 84 B 7) como una manifestación exacerbada de erōs, y este a su vez como una duplicación de los apetitos, supuestamente boicoteadores naturales para Platón de un pleno ejercicio de la razón, sea aquí máximamente valorada por el filósofo ateniense, particularmente en su forma erótica, si bien con la restricción de que debe ser de origen divino (cf. 244a; 265a).

Las principales interpretaciones de esta insólita apología platónica de la locura en el Fedro, y, en particular, del amor como la mejor especie de esta pueden sistematizarse como sigue.

RD: Interpretación racionalista dialéctico-discursiva. Según autores como Rowe (1990, pp. 237-246), el logro por parte del filósofo del máximo desarrollo de la capacidad intelectiva de su alma para dar cumplimiento al objetivo gnoseológico de reconstruir la cartografía eidética, requiere asimismo un dominio solvente de sus fuentes irracionales de motivación, particularmente de los apetitos sexuales, en otras palabras la adquisición plena de la enkrateia. La mania erótica resulta ser entonces un estado psíquico que se cura y supera con el ejercicio de la razón en su modalidad discursiva a través del método dialéctico descrito en la Segunda Parte del diálogo. ${ }^{2}$ En todo caso si Platón de algún modo la rescata solo lo hace en tanto el amor del filósofo por la Forma de la Belleza pasa a reemplazar la pasión erótica por el bello amado. De modo similar Dodds (1980, pp. 71-102; 195-220) en su clásico estudio Los griegos y lo irracional había interpretado la valoración positiva de los distintos tipos de locura divina como una concesión platónica al "conglemerado heredado" para mejor comunicar sus tesis a una audiencia no iniciada en la filosofía, pero sin que ello implicara en realidad renuncia alguna a sus principios racionalistas.

2 De modo similar Rowe (1986, pp. 106-125) defiende el carácter "tardío" o “de transición a la vejez" de este diálogo, al interpretar que la propuesta del método dialéctico de unión y división en la Segunda Parte del Fedro, particularmente como modo de discusión "en vivo", supone una crítica implícita, a su vez que una propuesta superadora, al discurso mítico donde Platón aparentemente defiende la mania erótica de origen divino y a la teoría de la reminiscencia a ella aquí asociada como modo de explicar el acceso al entramado eidético. 
IM: Interpretación intuitivo-mística. Según Price (1992, pp. 243-245) en el mito del carro alado del Fedro Platón haría un reconocimiento de un nuevo rol de la razón: la intuición de la realidad eidética puesto que el filósofo enloquecido de amor, ante la belleza física del joven, tendría una captación anticipatoria de la Forma de la belleza, previa a la reconstrucción reflexiva de la cartografía de lo real a través del trabajo rememorativo-dialéctico. También para Seeskin (1976, pp. 574-586) la experiencia de la locura amorosa que desata la hermosura corporal del amado desencadena en el filósofo el amor a la sabiduría que lo impulsa a la intuición directa de las Formas. A ello agrega que Platón describe la mania erótica del filósofo en términos de las instancias culminantes de los cultos mistéricos no por razones de expresividad retórica ni para expresar meramente un estado epistémico en el que se alcanza el conocimiento de entidades abstractas o universales, sino porque esta locura amorosa posee asimismo un carácter religioso y, en última instancia, místico en la unión del alma con una dimensión divina, la de las Formas. ${ }^{3}$

IRR: Interpretación irracionalista. En el Fedro Platón reivindicaría el papel de lo irracional en la motorización de la búsqueda de la sabiduría por la razón. En tal sentido, Nussbaum (1986: 79-124), representante más conspicua de esta posición, sostiene que en este diálogo los elementos no-intelectuales, como los apetitos -usualmente vituperados en escritos como República y Fedón -, y, en especial, la locura erótica, son valorados principalmente por tres motivos: ser fuentes necesarias de energía emocional; ser guías fundamentales en nuestro anhelo por el conocimiento; ser ellos y las acciones que provocan componentes intrínsecos del mejor modo de vida. Para Price (1992, pp. 244-245), el deseo sexual también cumple un papel positivo, pero solo en forma accidental puesto que el objetivo metafísico que inspira supone en realidad la frustración de su cometido: la concreción de la unión sexual. ${ }^{4}$ También para

${ }^{3}$ No obstante, se trataría en el caso de Platón de un misticismo que no implica una unión absoluta con lo divino, puesto que el alma conserva su individualidad incluso en estado desencarnado. Vid Seeskin 1976, p. 577.

${ }^{4}$ Vlastos (1981, p. 40), por su parte, sostiene que en el amor filosófico el intercambio intelectual se combina con la atracción sexual y el deseo físico si bien no se consuma. En el extremo opuesto a IRR, Rowe (1990, pp. 227-246), señala que el filósofo puede "curarse" en su existencia actual de la locura erótica cuando el auriga (la razón) doma y somete al díscolo corcel negro. 
Ahonen (2014, pp. 38-40) Platón, aunque en general censura la locura, valora en el Fedro los tipos de locura de origen divino, especialmente la erótica, en tanto el amor físico permite el brote inicial de las alas del alma que han de conducirla a la contemplación de la belleza en sí; no obstante, el amante-filósofo, idealmente, tendría que apaciguar su deseo sexual.

En el presente trabajo intentaré mostrar que en el Fedro la mania, en tanto estado alterado de conciencia, representa para Platón desde un síntoma de un máximo desequilibrio psíquico y una corrupción ético-cognitiva hasta un estado mental privilegiado, propio de la locura profética, catártica, poética y, particularmente, de la erótica. Para ello me ocuparé sobre todo de los debates en torno a IRR, $y$, en forma derivada, a cómo pueden articularse en mi interpretación elementos de IM y RDD. Así, tras referirme brevemente a los elementos ya existentes en el contexto cultural que Platón retoma en su compleja concepción de la locura, me centraré en el análisis de los rasgos comunes y diferenciales de de erōs en tanto locura erótica de acuerdo a las definiciones "sintéticas" de la mania amorosa que, a través del método de unión y división (Dixsaut, 2001, pp. 118-119; 124-132), brinda el propio texto. En tal sentido mostraré que:

i. En el Primer Discurso de Sócrates (238b-c) la definición de erōs como "apetito connatural por los placeres" e irracional vs. la "opinión adquirida orientada a lo mejor" (equiparada aquí a la sōphrosynē como perfección de la enkrateia), ya sugerida a través de la descripción del amante en el Discurso lisíaco (230e-234c), presenta la locura erótica como reñida con la razón, en concordancia con la visión del sentido común.

ii. El Segundo Discurso de Sócrates (243e-257c) constituye una instancia superadora a esta alternativa al proponer que: a) tanto en la locura amorosa ordinaria como en la de origen divino existe una exacerbación del apetito (epithymia) sexual en el amante ante la belleza física del amado que causa una percepción y modo de actuar que se aparta de los parámetros normales; b) no obstante, ambas se diferencian en que, mientras en el caso del erōs "izquierdo" (266a) este queda reducido a su expresión apetitiva y se desarrolla sin freno, en el del erōs "derecho" (266a) 
precisamente la renuncia a la satisfacción sexual no solo impulsa sino que exacerba el amor a la sabiduría, tanto en el amante como en el amado, y estimula así en la parte racional del alma el deseo de captación de la belleza en sí.

iii. Finalmente me referiré a cómo IM y RDD son presentadas en el contexto del mito como formas de anamnēsis. Por una parte, el verdadero amante enloquecido de amor por el joven, rememora, gracias a la belleza en él presente y de un modo más o menos consciente, una captación directa y extra-discursiva de un ámbito divino y trascendente. Esta modalidad de la razón sería, no obstante, estimulante a la vez que complementaria -no meramente anticipatoria- a los ineludibles esfuerzos del trabajo dialéctico-argumentativo y reflexivo de la razón (RDD), descrita en el mito como reconstrucción rememorativa del entramado eidético. A ello se agrega un tercer tipo de anamnēsis consistente en recordar el tipo de configuración psíquica divina correspondiente a nuestra alma a través de la contemplación de la estructura isomórfica del alma del amado; en el caso de los amantes filósofos, se trataría de un alma "tipo Zeus", que representa el ideal de una cómoda conducción de los aspectos irracionales al estar sustentada en un satisfactorio cumplimiento de los anhelos de la razón.

1. Locura humana y locura divina en el contexto cultural griego: el caso de la mania erótica

Ya en Homero el verbo mainomai significa: (a) "estar preso de un ardor furioso" (Hom. Il.5.717, 6.101; Od.ix.350); (b) "estar borracho" (Hom. Od.xviii.406; 21.298); (c) "estar fuera de sí por algún tipo de intervención divina" (Hom. Il.vi 132; S. Ant.1152), mientras que mania refiere de modo más restringido a la locura (cf. Hdt.6.112) y predominantemente al "frenesí de inspiración divina" como, e.g., en E. Ba.305 (vid. LSJ y $D E L G$, s.v. maínomai y mania). Estos diversos significados remiten, no obstante, de distinto modo a la noción de "pensar" asociada a la raíz * men en indoeuropeo y manen griego en tanto en todos los casos la capacidad normal de juicio es reemplazada por un estado mental alterado. Como señala Ahonen (2014, pp. 13-14), mania era el vocablo griego -su equivalente latino sería insania- más comúnmente empleado en la 
antigüedad para referirse un "estado severo de perturbación", y en tal sentido su vinculación con el término ektasis implicaba un "estar fuera de sí" en el sentido de una "distorsión" -alienatio- de la mente, la cual se manifestaba en un comportamiento desviado de los parámetros estándar de racionalidad y en el que la persona afectada presentaba características y comportamientos inusuales.

En el entramado de la cultura griega, por otra parte, ya encontramos los dos tipos de mania que se distinguen en el Fedro (así como en otras partes del corpus platonicum): ${ }^{5}$ la locura ordinaria, producida por causas naturales, y la locura divina, de origen sobrenatural.

En efecto, por un lado, había una mirada netamente negativa en la que se la entiende como una enfermedad mental, o al menos como un síntoma fruto de un desequilibrio somático (Ahonen, 2014, pp. 10-18). Así ya Heródoto en Historias 3.33 atribuye la locura de Cambises a una epilepsia congénita y reflexiona sobre cómo las perturbaciones del cuerpo afectan necesariamente a la mente. Pero es en los tratados hipocráticos -sobre todo en el De la enfermedad sagrada-, tal como señala Ahonen (2014, pp. 10-13) donde más claramente la mania es considerada como un conjunto de síntomas psíquicos (alucinaciones, representaciones ilusorias, temores) ocasionados por un desequilibrio en los elementos del cuerpo (que es donde se daría el estado propiamente de enfermedad), el cual afectaba sobre todo al cerebro. Así, por ejemplo, atribuye la epilepsia a un bloqueo en la distribución de aire que regula el cerebro, y la

\footnotetext{
${ }^{5}$ Hallamos un ejemplo de mania ordinaria en la obra platónica en $R$. 1.331 c donde, ante la definición de que la justicia es dar a cada uno lo que le corresponde y decir la verdad, Sócrates objeta que, no obstante, no habría que devolver a un amigo que se ha vuelto loco (maneis) sus armas. A estos conceptos de "locura no-divina", Platón agrega el concepto de "enfermedad del alma", como una degradación y corrupción ético-cognitiva de esta, equiparable a la "enfermedad del cuerpo" (e.g. Grg. 464b-466a), como en el caso del alma máximamente degenerada del tirano en $R$. 9.571a-576c (vid. McNeill, 2001, pp. 235-268). En cuanto a las formas de locura divina son valoradas pero a su vez contrapuestas al conocimiento racional. Así en lón 534b se establece un contraste entre aquellos que operan "con técnica" (technēi) con los que actúan "poseídos por el dios" (entheos) y "fuera de sí" (ekphrōn), como los poetas, rapsodas y emisores de oráculos; también en Ap. 22b-c Sócrates afirma que los poetas, tal como los profetas y adivinos, actúan no por sabiduría (sophia) sino por "un don natural e inspirados en un dios" (physei tini kai enthousiazonte). Por otra parte, en Banquete se centra en ofrecer los mejores elogios posibles al Amor, y ensalzarlo, sobre todo en tanto deseo por lo bueno y la sabiduría (cf. Smp. 203d; 204b; 204e-206a).
} 
locura, a un exceso de humedad que distorsiona las funciones cerebrales (Morb. sacr. 14.2-5; Joaunna; Ahonen 2014, pp. 12-13).

Por otro lado, existía también un concepto de locura entendida como el enajenamiento subjetivo originado por la intervención de alguna divinidad que, dada su procedencia, recibía una valoración positiva. No obstante, los efectos de la locura divina no eran siempre vistos como benéficos. ${ }^{6}$ Como observa Dodds (1980, p. 71) en el mismo Phdr. 244b se sugiere que la mayoría consideraba a la locura como "algo deshonroso", un oneidos. Asimismo no existía una clara demarcación entre la mania como enfermedad y la mania como delirio divino. Por una parte, la atribución de la locura a causas sobrenaturales era probablemente la que predominaba desde antiguo en el pensamiento popular, incluso tras la aparición de las explicaciones científicas como las de los tratados hipocráticos (vid. Dodds, 1980, p. 74). Pero, por otra parte, la locura divina era también interpretable por muchos simplemente como un estado patológico. Así por ejemplo, en el caso del delirio báquico, quien se encontraba poseído por Dioniso alcanzaba esa condición a través de la embriaguez, que ocasionaba en él un desequilibrio somático y con ello mental, desde el punto de vista de la etiología natural. De igual modo respecto de la locura de Cleómenes Heródoto la considera enviada por los dioses como castigo a un sacrilegio; no obstante, comenta que sus conciudadanos la atribuían simplemente a la ingesta excesiva de vino, costumbre que Cleómenes habría adquirido de los escitas (cf. Hdt. 6.84; 6.75). Dicho de otro modo, la locura ordinaria, entendida como enfermedad, y locura divina referían a menudo a una misma condición somática y mental, y la diferenciación entre una y otra se basaba sobre todo en cómo se interpretaba dicho estado psicofísico alterado del sujeto.

En cuanto a los cuatro tipos de mania divina que distingue Platón en el Fedro se corresponden con estados ya descritos en la tradición como un enajenamiento mental provocado por la intervención de un dios.

En lo que se refiere a la "locura profética", pueden citarse las figuras legendarias de Tiresias o Casandra pero el caso paradigmático, mencionado en 244b

\footnotetext{
${ }^{6}$ Sobre los efectos negativos de la locura enviada por los dioses vid. también Ahonen (2014, pp. $32-4)$.
} 
junto con las sacerdotisas de Dodona, ${ }^{7}$ era sin duda el de la pitonisa del templo de Apolo délfico, quien recibía mensajes directamente del dios, el cual ingresaba en ella, tomaba su cuerpo -en tal sentido la Pitia se hallaba "inmersa en el dios" (en-theos) ${ }^{8}$ y, cuando entraba en trance, se valía de sus órganos fonadores para verter en primera persona los oráculos (Dodds, 1980, p. 77). En cuanto al arte de la adivinación a través de señales enviadas por los dioses -la oionoistika-, implicaba ya, tal como se acota en 244c-d, un cierto grado de racionalización humana y, por lo tanto, un contacto menos inmediato con el dios. ${ }^{9}$

Respecto a la "locura teléstica, iniciática, o catártica", se creía que esta permitía la liberación de antiguas culpas y enfermedades de origen divino a través de ritos religiosos, en otras palabras, que la sanación de un mal de este orden, enviado por los dioses, solo era posible si se lograba a su vez la intervención positiva de estos. La "purificación" -katharsis- por medio del agua o del fuego era la forma habitual de evitar o curar la contaminación producida por diversas enfermedades, pero cuando se consideraba que la mania había sido enviada por los dioses, la cura estaba a cargo de los sacerdotes purificadores. ${ }^{10}$

En cuanto a la "locura poética", por la cual el artista es inspirado por los dioses, era un tópico ya establecido desde antiguo en la literatura griega. Así a Homero las

7 El santuario de Dodona estaba dedicado a Zeus y Dione y ya es mencionado por Homero (Hom. Il.xvi.231-235; Od.xiv.32, xix.296-298). Vid. Burkert (2007, p. 156).

${ }^{8}$ La Pitia constituía el epítome griego de la adivinación inspirada -enthousiasmós- consistente en un estado de conciencia alterado en el cual se supone la persona está "poseída por el dios" entheos-. Las sibilas habrían sido un grupo de mujeres vaticinadoras vinculadas a distintos santuarios. En tiempos de Platón se hacía referencia solo a una única Sibila, mencionada por él en 244b, y también por Aristófanes (Pax.1095) y Heráclito (22B92). Vid. Burkert 2007, pp. 150-161; 160-1 y Flacelière (1965, pp. 39-78).

${ }^{9}$ En este tipo de operatoria para vaticinar el futuro los presagios se realizaban por inducción e interpretación de signos concretos, tales como el vuelo de los pájaros, las entrañas de los animales sacrificados o algunos fenómenos atmosféricos o celestes. De tales prácticas evolucionaron ciencias como la meteorología, la astronomía o la astrología (vid. Burkert, 2007, pp. 152-155 y Flacelière, 1965, pp. 26-38).

${ }^{10}$ Los ritos dionisíacos, recreados en las Bacantes de Eurípides, son el prototipo de la mania de tipo catártico, (cf. 265b). También puede citarse el ejemplo de Orestes en las Euménides de Esquilo. También serían curables a través de la locura teléstica las enfermedades hereditarias provenientes de alguna antigua culpa, como en el caso de los Labdacidas. En cuanto a la epilepsia, considerada ya en la antigüedad hereditaria, constituía el epítome de las enfermedades de origen divino. En efecto, la misma palabra griega epílepsis remite al "ser tomado" -epi-lambánein- por una fuerza externa, lo cual muestra que se la relacionaba con el estar poseído por un poder sobrehumano y divino (vid. Burkert, 2007, pp. 110-114 y Hackforth, 1952, pp. 59-60). 
Musas -intermediarias entre dioses y hombres- le comunican "los hechos pasados, presentes y futuros" (Hom. II.i.70; ii.484-492; Od.xii.191); ${ }^{11}$ Hesíodo, también recibe de ellas, hijas de Zeus y Mnemosyne (Hes. Th.52-53; 915-918) un conocimiento de este tipo (Hes.Th.38). No obstante, cabe aclarar, que, si bien la tradición literaria en la que Platón se inserta reconocía que el poeta recibía inspiración de las Musas, esto no implicaba ausencia del conocimiento de su arte (vid. von der Walde, 2010, pp. 33-48; Naddaf, 2009, pp. 63-73).

Ahora bien, en lo que refiere particularmente a la mania erótica, aun en los casos en que se le reconociera una ascendencia divina, aparece mayormente concebida en las fuentes literarias como aciaga y cáustica para el sujeto afectado, según se evidencia repetidamente en la tragedia y tal como se puede ejemplificar a través del coro de la Antígona de Sófocles (vv. 781-801) dos de cuyos versos más representativos son los siguientes:

Quien te posee [Erōs], enloquecido queda (memēnen). Tú asimismo arrancas de los hombres justos pensamientos (phrenas) injustos para [su propia] ruina (vv. 793-94).

La estrategia de Platón en el Segundo Discurso de Sócrates del Fedro sería la de reivindicar la locura erótica por asociación con las otras formas de mania divina mejor consideradas en la cultura en tanto medios de comunicación con un plano trascendente y, de hecho, jerarquizarla el mejor tipo entre ellas. De este modo supera la antinomia del sentido común entre "deseo sexual" vs. "razón" que recoge en el Discurso lisíaco y en el Primer Discurso de Sócrates, y transforma a erōs en el propulsor fundamental del anhelo por la sabiduría.

\section{Tipos de mania erótica: características comunes y diferencias específicas}

${ }^{11}$ Cf. Hom. Od.xxiv.60, si bien en Od.i.1 se hace referencia a "la" Musa y en Il.i.1. se alude a ella como "diosa" que narrará la cólera de Aquiles, es decir los hechos acaecidos en el último año de la Guerra de Troya. 
En la Segunda Parte del Fedro se realiza una aplicación ejemplificadora del método de "unión y división" a fin de distinguir, en base a lo ya discriminado, sobre todo, en los dos discursos de Sócrates (cf. 238d-241d; 249d-257a), dos tipos de erōs, correspondientes a los dos tipos de mania, uno censurable -el izquierdo- y otro benéfico -el derecho- que comparten no solo un nombre común, siendo homónimos, sino también un correlato objetivo o género en común "la falta de juicio de la mente". Leemos así en 266a-b:

Y así como los discursos incluían precisamente en una única forma común la falta de juicio de la mente (to aphron tēs dianoias), del mismo modo que de un cuerpo único hay por naturaleza partes dobles y homónimas denominadas "izquierdas" y "derechas", así también ambos discursos, han considerado nuestra locura (to tēs paranoias) como una forma única por naturaleza. Uno de ellos, después de cortar la parte izquierda y volver de nuevo a cortar esta, no paró hasta encontrar en estos cortes un amor llamado "izquierdo" que con toda justicia reprobó. El otro, en cambio, al conducirnos hacia la parte derecha de la locura (tès manias), y encontrar y poner ante nosotros un amor que es homónimo del otro pero, a su vez, divino, lo alabó como el responsable para nosotros de los más grandes bienes. ${ }^{12}$

Lo que me propongo aquí es reconstruir las definiciones "sintéticas" ${ }^{13}$ de erōs como locura que se desarrollan en los discursos de la Primera Parte del diálogo y que se reorganizan en esta sección de la Segunda Parte dialécticamente. En tal sentido se verá

\footnotetext{
${ }^{12}$ To aphron tēs dianoias y paranoia son aquí nombres alternativos a mania aplicados a un mismo género: la locura. Vid. Ryan (2012, ad loc).

13 La dialéctica designa para Platón en sentido amplio la habilidad de pensar y hablar correctamente lo que es, a través del entrelazamiento de lo uno y lo múltiple tanto en el pensamiento como en el lenguaje, en correspondencia con la estructura de lo real (vid. Dixsaut, 2001, pp. 9; 103-132), no por recopilación de generalizaciones subjetivas. Con esta versión del método dialéctico que se ofrece en el Fedro como arte de "unión y división" no se intenta, como en R. 509d-511e y Smp. 209e-212b, la deducción de una explicación de la realidad a partir de un principio único, sino la definición de las entidades a través de la reunión y división de acuerdo a géneros y especies pero, también, de modo más general, por medio de toda articulación apropiada de elementos múltiples en una unidad no sensible (una "definición sintética", como dice Dixsaut (2001, pp. 118-119). Como señala Dixsaut (2001, pp. 11011) contra, entre otros, Robinson (1953, p. 66) y Griswold (1986, pp. 178-179), la no reducción de la definición a la clasificación en géneros y especies permite disolver la supuesta inconsistencia de que Platón caracterice aquí la dialéctica de un modo que estrictamente él no aplicaría a su propia construcción de los argumentos del Fedro. Para ello es necesario también comprender que la idéa no es necesariamente una Forma metafísica sino toda unidad no sensible desde la que se puedan reunir correctamente elementos múltiples. Vid. Dixsaut (2001, pp. 103-139; 2004, pp. 11-37).
} 
que, tras establecer una oposición entre deseo y razón en los dos primeros discursos, surgiría del Segundo Discurso de Sócrates una propuesta superadora en tanto la razón no sería otra cosa que la expresión más elevada y potente de la locura erótica por la belleza. Cabe señalar que este tratamiento dialéctico y orgánico de la mania se encarna a su vez en la puesta en escena y presentación dramática que Platón cuidadosamente trabaja en el Fedro y predica hacia el final del diálogo como ideal a alcanzar de todo texto escrito (vid. Diolaiti, 2017, pp. 33-38), si bien este es un punto que aquí no podremos desarrollar.

\subsection{La caracterización de la locura erótica humana en el Discurso lisíaco y el Primer Discurso de Sócrates}

En el Discurso lisíaco que lee Fedro encontramos una primera caracterización negativa de la locura erótica humana en oposición al sano juicio (sōphrosynē). ${ }^{14}$ Allí el típico hombre mayor de la relación homofílica característica de la Atenas de ese tiempo que quiere conseguir los favores sexuales de un bello muchachito, arremete, tras fallidos intentos previos, con el planteo de que el joven debe elegirlo y gratificarlo por ser él un no amante en lugar de un amante, o al menos eso es lo que manifiesta. El concepto de amor que está a la base de este discurso es el de un erōs puramente físico, puesto que se describe al amante como mayormente interesado en el cuerpo del bello muchacho ("En efecto muchos de los que aman desean el cuerpo antes de conocer la forma de ser y volverse versados en otros rasgos personales." 233a). El argumento fundamental que allí se desarrolla es que, mientras que el no amante, al no

${ }^{14}$ Sōphrosynē tiene en su composición una alusión al estar "sano" y "a salvo" -sōs- y al ser "sabio" -phrónimos- de acuerdo a la idea homérica de que el diafragma -phrēn- era el centro no solo de las emociones, sino también de los pensamientos y la voluntad. Refiere así un "sano juicio" en el sentido de "sabiduría moral", de ahí la otra traducción usual por "temperancia", "moderación". Se sugiere de este modo una oposición fundamental que se tematiza y cuestiona de diversos modos en las distintas secciones del Fedro: erōs = enfermedad = falta de control = falta de juicio versus no- erōs = salud = autocontrol = juicio/conocimiento. Vid. también n. 16 infra. Para Platón el conocimiento de lo auténtico bueno por parte de la razón es fundamental para lograr la perfección del autodominio -la enkrateia- al punto que, para algunos, la virtud de la sōphrosynē debe entendérsela en el pensamiento platónico más bien como "sano juicio" o "sensatez" que como "moderación", tal como parece desprendería del análisis del Cármides (vid. Rowe, 2007, p. 36, n. 113). No obstante, como se tratará de mostrar en el presente trabajo a propósito del Fedro, el conocimiento de la realidad eidética no reemplaza sino que consolida la moderación de los apetitos. 
estar obnubilado por sus sentimientos, será capaz de hacer lo que sea bueno y útil para ambas partes, el amante, al no poder substraerse del estado patológico de enamoramiento y no estar en sus cabales, aun dándose cuenta de esto, no podrá dominar su pasión y solo proporcionará daño al objeto de su amor. Leemos así en 231c-d:

$\mathrm{Y}$, a decir verdad, ¿cómo sería verosímil entregar un asunto de este tipo [i.e. la gratificación sexual por parte del joven] a alguien que está en una circunstancia tan calamitosa que nadie con experiencia en ella haría siquiera el intento de sustraerse? Pues incluso ellos mismos [i.e. los que están enamorados] admiten estar más bien enfermos que en su sano juicio (nosein mallon è sōphronein), y saber de su desatino (eidenai hoti kakōs phronousin), pero no ser capaces de dominarse (hautōn krattein). Así que, habiendo recuperado el sano juicio (eu phronēsantes), ¿cómo podrían considerar que están bien esas cosas sobre las que deciden en tal estado?

Vemos entonces que en el Discurso lisíaco, si bien no se utiliza el término mania ni se da todavía una definición, se asocia el erōs del amante por los encantos físicos el bello muchacho con una enfermedad y se lo caracteriza como falta de dominio en oposición al "sano juicio" que regula la conducta del no amante.

El Primer Discurso de Sócrates defiende la misma tesis que el del lisíaco: que es mejor que los muchachitos bellos retribuyan con sus favores sexuales a los no amantes más a que los amantes. Pero, a diferencia del discurso del logógrafo Lisias, aquí no cuenta la mera acumulación de argumentos verosímiles y persuasivos a favor del no amante y en contra del amante, sino establecer, aplicando el método dialéctico de "unión y división" que se trata en la Segunda Parte (267b; 272d-e), las características esenciales de erōs para luego derivar de modo necesario en la segunda sección los efectos negativos de este. La realidad (ousia) misma de erōs es expresada así a través de una definición sintética según la cual es una de las formas de los principios factibles de gobernar nuestra existencia -la fuerza (rōme) del deseo (epithymia) que se dirige con desmesura (hybris) hacia los placeres vinculados a la belleza corporal, en alianza con el resto de los apetitos- en oposición a otro principio rector -la opinión adquirida 
que aspira a lo mejor, cuya expresión más acabada es la sōphrosyne.$^{15}$ Leemos así en

237d-238c:

Además, se debe comprender que en cada uno de nosotros hay dos formas que nos rigen y guían, a las cuales seguimos a donde sea que nos lleven: la una es el deseo connatural por placeres; la otra, es una opinión adquirida, que aspira a lo mejor. Estas formas a veces concuerdan en nosotros, pero a veces están en lucha. Así pues, si la opinión conduce por razonamiento a lo mejor y domina, el nombre para este predominio es "moderación"/ "sano juicio" (sōphrosynē ). Pero si el deseo irracional arrastra a los placeres y rige en nosotros, a este régimen se lo llama "desmesura" (hybris). ${ }^{16}$ Ahora bien la desmesura tiene muchos nombres, pues tiene muchos miembros y muchas partes, y de entre sus formas la que resulta ser preminente otorga al poseedor su denominación, una ni bella ni digna de adquirirse. [...] Así pues el deseo sin razonamiento, que domina cualquier opinión que tiende a lo correcto, conducido hacia el placer de la belleza, a su vez fuertemente fortalecido por el efecto de deseos congéneres en procura de la belleza de los cuerpos, y victorioso en la conducción, al tomar la denominación de su propia fuerza (ap'tēs rōmes), se llama "amor". ${ }^{17}$

Asimismo este erōs de origen físico definido como un tipo de deseo (epithymia) que está vinculado al placer en la belleza física y constituye a su vez una forma de desmesura (hybris) es asociado explícitamente con la locura humana en este Primer Discurso de Sócrates $(241 a)^{18}$ y también en el comienzo de la palinodia (244a). ${ }^{19}$

${ }^{15}$ Se traza aquí un contraste entre la compulsión de los deseos irracionales por los placeres y las inclinaciones mediadas por la racionalidad. En tal sentido sōphrosynē significa "moderación". Sin embargo, no deja de estar presente la idea de "sano juicio" al estar asociada al predominio de la "opinión que aspira a lo mejor".

${ }^{16}$ Hybris ("desmesura") era un término clave en el pensamiento moral y jurídico griego. Refiere a una acción brutal que violenta las reglas y origina así la venganza, en muchos casos divina, y, con ello, la situación trágica. Dos ejemplos típicos son el comienzo de la llíada con la cólera de Aquiles o en Odisea la conducta de los pretendientes. Vid. DELG, s.v. hybris. Aquí refiere al exceso en la búsqueda de los placeres.

${ }^{17}$ Sócrates vincula aquí erōs con rōme ("fuerza”) y sus cognados. Platón juega así una vez más con las etimologías a la vez que establece algo en serio, pues esta primera definición de erōs será retomada en la Segunda Parte como la forma "siniestra" de una misma "fuerza", mientras que en la palinodia, erōs es la fuerza del alma para elevarse hacia la verdad (266b).

18 "Y justamente en ese momento, en que se debe retribuir por los servicios, tras cambiar el amante dentro de sí por otro dirigente y líder -el intelecto y el sano juicio en lugar del amor y la locura-, y volverse otra persona, el muchachito no se da cuenta de esto."

19 "Y se debe expresar de este modo: 'no es fidedigna la historia' que diga que, estando a disposición el amante, se debe gratificar más bien al no amante, nada más que porque el primero está, 
A través de la antítesis que se traza aquí entre erōs como apetito dominante versus el control sobre los placeres a través del juicio, este Primer Discurso de Sócrates ofrece un análisis en el que están ausentes elementos típicamente platónicos, tales como la inclusión de lo irascible -tercer aspecto del alma en República, junto con lo apetitivo y lo racional-, y de la clásica diferenciación entre doxa y epistēmē de diálogos como Menón (97b-99a), República (5.476c-48a) y Timeo (51d-e). Si bien esta aproximación bipartita, que resalta, además, el carácter connatural, irracional y compulsivo del primer principio frente a la índole adquirida, racional y deliberativa del segundo, se acerca a la visión del sentido común (Hackforth, 1952, pp. 41-42) -de hecho es en gran medida una sistematización y explicitación de los supuestos con que opera el Discurso lisíaco para dar una explicación verosímil a su audiencia-, se la puede igual considerar una formulación igualmente "platónica", sólo que adaptada al contexto de enunciación (Rowe, 2000, p. 154; vid. también Lozano Nembrot, 2016, pp. 30-36). Se trata ante todo de un "discurso de transición" (Poratti, 2010, p. 309), entre otras cosas porque prepara conceptualmente el terreno para el modelo antropológico que se sugiere luego en el Segundo Discurso a través de la imagen del carro alado. Por otra parte, la forma del principio rector de "la opinión adquirida que aspira a lo mejor" evoca la ética del intelectualismo socrático de diálogos considerados "tempranos" o "transicionales" hacia la madurez, como el Gorgias y el Protágoras, si bien no hay aquí una diferenciación entre la opinión que apunta a lo que "parece mejor" -y puede o no coincidir con lo mejor- y el conocimiento de lo que es realmente mejor-que es lo que todos queremos (vid. Segvic, 2000, pp. 1-45). La circunstancia de que este principio ético-epistémico pueda ser dominado por los apetitos dirigidos a los placeres corporales alude a la posibilidad de la akrasia -"incontinencia"-, la cual no tiene cabida, en principio, en el intelectualismo socrático -según el cual siempre obramos, equivocados o no, de acuerdo a lo que creemos o, a veces, conocemos que es mejor (cf. Prt. 358b-d; 345c-e) -, y que el Platón maduro reformularía al incluir en su

en efecto, loco y el otro en su sano juicio. Pues si fuera cierto sin más que la locura es algo malo, se expresaría bien. Pero en realidad los más grandes bienes se generan para nosotros gracias a la locura, siempre que sea otorgada por un don divino." 


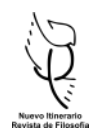

María Angélica Fierro

psicología aspectos irracionales del alma (cf. $R$. $439 \mathrm{e}-440 \mathrm{a}),{ }^{20}$ como los que se mencionan en este Primer Discurso de Sócrates y que son retomados y reformulados en el modelo del alma que se plantea a través del símil del carro alado.

\section{Locura erótica humana y locura erótica divina en el Segundo Discurso de} Sócrates: similitudes y diferencias ${ }^{21}$

a) Similitudes: apetito sexual exacerbado; alteración del estado psicofísico y de la conducta en el enamorado

Frente a erōs como forma de mania contraria al control de las apetencias carnales y nociva para el buen juicio en general y para la filosofía en particular descritos en el Discurso lisíaco y en el Primer Discurso de Sócrates, Platón realiza en el Segundo Discurso de Sócrates una curiosa defensa de los cuatro tipos de mania de origen divino, especialmente de la locura amorosa en tanto otorgada por los dioses. Pese a sus diferencias, la locura amorosa humana y la locura amorosa divina comparten un origen común: el deseo (epithymia) intenso que despierta en el amante la percepción visual de la belleza corporal del amado.

Cuando el amante apasionado por la belleza del muchacho queda detenido en el nivel corporal y solo desea abalanzarse sobre él y concretar sus apetencias carnales, tiene lugar la "locura erótica ordinaria", que es pura desmesura (hybris) que busca complacerse y aprovecharse de los encantos físicos del amado (250e-251a), tal como venía caracterizándose a erōs en los dos discurso anteriores. Leemos así en 250e-251a:

${ }^{20}$ La concepción de la akrasia del Protágoras podría, no obstante, suponer el tratamiento de República. Vid. Morris (2006, pp. 195-229).

${ }^{21}$ En la locura erótica ordinaria el amado permanece en un rol pasivo de objeto de amor y es valorado principalmente por sus atractivos físicos, e intercambiable por cualquier otro de similares encantos. En la locura erótica divina, en cambio, ambos miembros de la relación pasan a ser sujetos amados y amantes (vid. Halperin, 1986, pp. 62-68), puesto que, como se desprende de 255e, el amante filósofo hace que el joven desarrolle un "contra-amor" (anterōs) y desarrolle su naturaleza filosófica (cf. 252d-253c). No obstante, el muchachito se convierte más exactamente en amante de su propia imagen y corresponde a su enamorado solo con philia (vid. Calame, 1992, p. 196). Por otra parte, en las parejas de filósofos ambos han de descubrir que, en último término, están enamorados de la Forma de la belleza, de la verdad. 
Así pues, quien no se inició o ha sido corrompido no es transportado rápidamente de aquí hacia allí, hacia la belleza en sí, al contemplar su homónimo acá. De modo tal que no actúa con reverencia ante ella sino que, entregándose al placer, se aboca a montarse a la manera de un cuadrúpedo y a inseminar. $Y$, conviviendo con la desmesura, no siente temor ni se avergüenza de perseguir un placer contrario a la naturaleza.

En el caso de la mania amorosa divina, pese a que se diferencia, como se trata en la sección siguiente de este trabajo en más detalle, en que tracciona al alma a la rememoración -anamnēsis - de las Formas, en especial de la Forma de la belleza (249b-250e), también se desencadena, como la locura amorosa ordinaria, ante la visión del hermoso cuerpo del amado y produce el surgimiento de un ardiente deseo. Solo que este es descrito como un "brote de las alas" por constituir para el amante filósofo un primer paso en el crecimiento de las alas del amor por la verdad:

En lo que se refiere a la cuarta forma de locura [i.e. a la locura erótica divina], cuando alguien, al mirar la belleza de aquí y recordar la verdadera belleza, empieza a echar alas $y$, con sus alas extendidas y un afán de elevarse pero sin poder hacerlo, dirige la mirada hacia arriba como un pájaro y desprecia las cosas de abajo, se lo toma con razón por loco. 249d

En 251c-d se detalla cómo la percepción visual de la hermosura corporal del amado -e incluso el recuerdo de esta percepción- impacta en el alma del amante y despierta en ella el ansia sexual (himeros) ${ }^{22}$ y la calienta, es decir hace que se emplume, mientras que la imposibilidad de verlo la reseca y atasca en ella el crecimiento de las alas del deseo: ${ }^{23}$

${ }^{22}$ Cuando la corriente que desata desde el exterior la belleza del amado fluye hacia el interior del alma, se transforma en himeros ("ansia, anhelo"), término que tiene a menudo, como aquí, connotaciones sexuales (cf. II.3.446). Platón construye en base a esta explicación un juego etimológico en el que vincula himeros con "lo que llega" (epionta) -participio del verbo epi-ienai ("Ilegar, avanzar")- y "lo que fluye" (reonta) -participio del verbo rein- en forma de "partículas" (merē). En Cra. 420a Platón también relaciona himeros con el "fluir" (rein).

${ }^{23}$ Antes de la primera caída en un cuerpo mortal, toda alma humana es alada, es decir, su erōs por la verdad la impulsa, con mayor o menor éxito hacia el plano eidético. Pero, una vez encarnada - 
Y, al ver al amado, a propósito de este estremecimiento, un cambio se apodera de él, un sudor y temperatura desacostumbrados. ${ }^{24}$ Pues el recién iniciado, al recibir el flujo de la belleza a través de los ojos, se calienta, y, debido a ello, el ala, por su naturaleza constitutiva, se irriga. ${ }^{25}$ Al calentarse, las partes en el contorno de donde nacen las alas se derriten, partes que antiguamente impedían el brote de estas, al haberse obstruido por el endurecimiento. Pero al fluir el alimento, el cálamo del ala se hincha e incita el crecimiento desde la raíz por debajo de toda la configuración externa ${ }^{26}$ del alma. (Mis itálicas)

Asimismo en la descripción tripartita del alma humana a través del símil del carro alado se afirma que toda el alma se enciende al captar la mirada del bello de modo que el impacto de la hermosura física también actúa sobre el auriga (la razón) y el caballo blanco (la impulsividad), si bien la compulsión por satisfacer la apetencia sexual es atribuida únicamente al caballo negro y tiene distintas resoluciones según se trate del alma de un amante filósofo o no. Leemos así en 253e-254ạ:

Así, cada vez que el auriga, al contemplar la arrobadora luz de los ojos del amado ${ }^{27} \mathrm{y}$, al encenderse con esta sensación toda su alma (pasan aisthēsei diathermēnas tēn psychēn) empieza a sentirse plagado de aguijones de cosquilleo y anhelo, el caballo obediente al auriga, sometido entonces y siempre a la vergüenza, se contiene para no abalanzarse sobre el amado. Pero el otro ya no hace caso ni de los espoleos ni del látigo del auriga, sino que se abalanza, brincando con violencia. (Mis itálicas)

esto es, en nuestra forma de existencia actual- depende de cada uno hacer crecer las alas de este deseo, para lo cual enamorarse es un facilitador en este proceso.

${ }^{24}$ Enamorarse provoca una situación inusual en el cuerpo y el alma de quien entra en este estado, descrito aquí de manera muy similar a como lo hace Safo (Fr. 31 Voigt; Yunis 2011, ad loc.).

${ }^{25}$ Es probable que haya aquí, como en Men. 76c, una referencia a la teoría de la visión de Empédocles (DK 31A86.7, 87, B89, 109a).

${ }^{26}$ Tomamos aquí el término eidos en su sentido usual. Cf. n 44 infra.

${ }^{27}$ Omma era utilizado poéticamente para referirse a los ojos y la cara en general como fuente de luz y, como consecuencia, de deleite (vid. Yunis, 2011: ad loc. y LSJ, s.v. omma). 
Por otra parte, los dos tipos de locura amorosa no solo coinciden en la intensidad del deseo sexual al percibir la belleza física del amado sino que en ambos casos esto origina un comportamiento inusual que evidencia un estado psicofísico alterado propio de la mania.

En efecto el afectado por la locura amorosa ordinaria es un enfermo (231d; 238e) cuya falta de juicio lo aparta de los parámetros habituales de sensatez y quien, al transformar al joven en su único centro de interés, así actúa y obliga a actuar al amado de modo extravagante, en pos de su objetivo de disfrutar sin límites y de modo exclusivo de sus encantos físicos. Así en el Discurso lisíaco el supuesto no amante señala que: el amante celoso sospecha obsesivamente de todos los que se aproximan al amado y hace que este se enemiste con todos los posibles competidores y quede aislado (232d); induce a una inversión respecto de lo que usualmente se considera penoso y placentero (233b); sus allegados lo reprenden por sus inapropiadas conductas (234b). El Primer Discurso de Sócrates retoma y amplia estos puntos (239a241d), y añade que el mayor daño del amante sobre el amado es alejarlo de la divina filosofía (239b) y perjudicarlo no solo en cuanto a su estado mental sino también físico (239c-d).

Similarmente el afectado por la locura amorosa divina presenta, a causa del impacto de la belleza física del amado, comportamientos totalmente atípicos para la mayoría que obedecen también a una comprensión del mundo inusual, si bien en su caso esto se debe a la intuición de un sentido trascendente que motiva acciones consideradas como estrafalarias por los más. En primer término, al tener su mirada y su deseo vueltos hacia la verdadera realidad pero sin poder "volar" hacia ella, muestra desprecio por los intereses mundanos (249d). ${ }^{28}$ Sufre asimismo un estado de angustia que incluso a él mismo le resulta atípico: se enfurece y enloquece, no puede estar en paz ni de día ni de noche, corre detrás del amado para hallar sosiego (251d-e). Esto desemboca en conductas inusuales respecto a su entorno, similares y aún más

28 “Por desatender las solicitudes humanas y llegar a estar próximo a lo divino, mientras es tachado por la mayoría como perturbado (parakinōn), pasa inadvertido a los muchos que está inspirado por el dios" 249d. 
exageradas a las atribuidas a los amantes en los discursos anteriores, tal como se expresa en 252a-b:

Como consecuencia de esto, el alma, por voluntad propia, no se aleja de la compañía del amado, ni valora a nadie más que al hermoso, sino que ignora a madres, padres y todos sus compañeros y, aun perdiendo su fortuna, debido a su negligencia, no le importa nada. Asimismo, con desprecio de todas las buenas costumbres y decoro, de los cuales antes solía enorgullecerse, está presta a esclavizarse y a recostarse, donde quiera alguien la deje, ${ }^{29}$ lo más cerca posible del objeto de su anhelo. Pues, además de reverenciar al poseedor de la belleza, ha encontrado en él el único sanador ${ }^{30}$ de sus grandes penurias.

b) Diferencias: descontrol/control del apetito sexual; reducción/expansión del erotismo; carnalidad e idealidad del amor platónico

Como se mostró en la sección a) ambos tipos de mania erótica suponen la exacerbación del apetito sexual ante la percepción visual de la belleza del amado. La diferenciación entre locura ordinaria y locura divina depende aquí, de forma similar a lo que ocurre en la diferencia que se establecía entre una y otra en el contexto cultural, de la interpretación que se hace de esta percepción y del consecuente estado psicofísico y modo de actuar.

En la locura erótica ordinaria el amante experimenta la intensidad de la pasión amorosa pero, sin poder trascender la percepción sensible de la belleza, queda detenido al nivel de la dóxa ${ }^{31}$ y se abalanza bestialmente sobre el amado para satisfacer sus apetitos carnales y disfrutar sin freno y con exclusividad de los atractivos físicos del joven hasta hartarse y reemplazarlo por un nuevo "juguete de sus amores". Se trata, por lo tanto, de un erōs necesariamente efímero y atascado en un nivel somático de expresión. En términos del modelo del alma tripartito, esto significaría que el apetito sexual -el caballo negro- actúa sin freno, mientras que la razón -el

${ }^{29}$ Cf. Smp.203d.

${ }^{30}$ Cf. Smp.189d; 193a.

${ }^{31}$ Después de caer y encarnar en un cuerpo mortal todas las almas humanas "se sirven de un alimento aparente/opinable" (trophēi doxastēi xrōntai, 248b). El filósofo será el que pueda elevarse de este nivel doxástico para restablecer, en la medida de lo posible (kata dynamin), el conocimiento de la realidad eidética $(249 c)$. 
auriga- es arrastrada por este, es decir, no puede transcender la percepción sensorial ni establecer autónomamente lo que es bueno para el alma en su totalidad; asimismo la impetuosidad -el caballo blanco- tampoco puede obedecer los mandatos de la razón de acuerdo a su respeto por lo honorable y su rechazo a lo deshonroso (250e251a).

En cambio, en la locura erótica divina, a partir de la impactante visión de un bello rostro o figura corporal y las ardientes ansias que despierta, al reconocer allí el amante simultáneamente la presencia de la belleza en sí, se activa en él el recuerdo de esta como el verdadero objeto de su amor a la vez que convierte al amado en un agalma, ${ }^{32}$ es decir en la representación del dios con el que psíquicamente se identifica, en el mejor de los casos con Zeus a quien emulan los filósofos (252c-e). Esto redunda no solo en una nueva comprensión sino también en el resurgimiento en la parte racional del anhelo por la verdad acompañado de deseos complementarios: querer venerar al amado como representante del dios y, además, controlar y no ceder a la satisfacción del apetito sexual. Esto se describe en 254a-e como un conflicto entre las partes del alma en el que la razón (el auriga) lucha, con la colaboración del caballo blanco (la impulsividad anhelante de honores), contra la violenta demanda del caballo negro para satisfacer sus deseos carnales. La resolución de la batalla del alma en el caso de los amantes filósofos se describe en $255 \mathrm{e}-256 \mathrm{~b}$ del siguiente modo:

Cuando yacen juntos los enamorados, el caballo desenfrenado del amante tiene algo que decir al auriga, y considera que obtuvo poca cosa a cambio de muchas penurias [...]. No obstante, por otra parte, su compañero de yunta, junto con el auriga, se resiste a estas cosas de acuerdo con la vergüenza y la reflexión. Así pues, si, al conducirlos a un modo de vida ordenado, esto es, a la filosofía, los mejores elementos de su mente prevalecieran (nikēsēi ta beltiō tēs dianoias), amante y amado transcurren su

32 Agalma se vincula con el verbo agallomai, que significa "enorgullecerse, vanagloriarse, regocijarse de algo" en relación, e.g., con las proezas en el campo de batalla (Hom. Il.iv.144), pero también en referencia a los sacrificios u ofrendas realizadas al rey o al dios (Hom. Od.3.438). Posteriormente se empieza a emparentar con "estatua en honor a un dios" (Hdt.1.131) y, de allí en adelante, con la noción abstracta de "imagen o representación pictórica" (E. Hel.262). En 251a el bello amado opera para el filósofo como la "imagen de un dios" que lo remite a lo bello en sí. También el enamorado Alcibíades descubre agalmata en el interior de Sócrates (Smp.216e). 
existencia actual en estado de dicha y paz interior, al ser dueños de sí mismos y estar bien organizados (enkrateis autōn kai kosmioi), por haber sometido eso por lo que la maldad (doulōsamenoi hōi kakia) se generaba en el alma y haber liberado aquello por lo que la excelencia (eleutherōsantes hōi aretē) lo hace.

Pero ¿en qué consiste este control de la razón de sus apetencias carnales en la locura amorosa de origen divino? ¿Implica acaso la eliminación de ellas? ¿O la convivencia de la atracción física con objetivos intelectuales? ¿Cumple el apetito carnal quizá un rol positivo, en realidad, para el logro de esos objetivos, junto con el de una vida armoniosa, al desencadenar el recuerdo de la Forma de la belleza, aunque sea de modo accidental? ¿O sin poder suprimir al caballo negro de nuestro interior, se trata, no obstante, de lograr desactivarlo para que el alma alcance la armonía bajo el liderazgo de la razón? ¿Queda reducido el control de los apetitos en el alma victoriosa a una epistēme? Una respuesta articulada a estos interrogantes (vid. aquí en la Introducción las distintas alternativas, expuestas, sobre todo en IRR) podría ser la siguiente:

i. Imposibilidad de eliminación del apetito sexual. No puede tratarse de eliminar este aspecto irracional de nuestro psiquismo. Tanto ahora, como en una hipotética vida post mortem, el alma humana/no-divina sigue siendo tripartita y conserva en su estructura esta obscura e indócil fuente de motivación. Incluso quienes, tras tres encarnaciones en una vida de tipo filosófico, pueden unirse a la caravana de los dioses al abandonar su cuerpo mortal, deben de todos modos, al término de diez mil años, reiniciar la "prueba" de ascenso al lugar fuera del cielo y batallar con su "caballo negro" una vez más (249a-b). ${ }^{33}$ La dimensión física de erōs, pues, en ningún caso puede ser extirpada de nuestra naturaleza humana, sino, en todo caso, doblegada y reconducida a modalidades amatorias superiores.

ii. Surgimiento del erōs metafísico a partir del erōs físico. El carácter sobrecogedor de la experiencia del enamoramiento, debido, al menos en primer

${ }^{33}$ Según Bluck (1958, pp. 156-164) el ascenso de las almas hacia el lugar fuera del cielo cada diez mil años no es automático sino de acuerdo a los méritos o deméritos alcanzados en sus existencias encarnadas. Para una posición contraria y determinista vid. McGibbon (1964, pp. 56-63). 
término, a la intensidad y exclusividad del deseo sexual por la persona bella amada, produce una crisis en la visión habitual del mundo del amante y abre la puerta a una comprensión distinta de sí mismo y de la realidad. Esta locura amorosa se vuelve divina cuando el amante presiente, además, en esa vivencia un sentido trascendente, aun si no lo puede explicar. ${ }^{34}$ En el amante-filósofo entonces su parte racional "recuerda" y capta la belleza en sí pero, a su vez, la percibe presente en el bello amado. Adquiere así una mirada y un deseo bidimensional: le impacta, reverencia y ama al joven por la belleza que ve en él y, a su vez, reconoce que lo que percibe y ama tiene un origen divino que sobrepasa su realización en ese individuo concreto. La atracción física entonces no solo convive con los objetivos y anhelos intelectuales sino que es necesaria para su puesta en marcha. En efecto, como ya se señaló, es al dirigir la mirada al hermoso cuerpo del muchachito y al recibir de allí partículas que llegan y fluyen que se despierta el ansia en el alma del enamorado, la cual empieza a "echar alas" y a manifestar su loco estado en diversos síntomas psicofísicos.

iii. Potenciación del erōs metafísico por renuncia al erōs físico: el amor platónico Entonces, al menos mientras nuestra alma sea habitante de un cuerpo, el impulso erótico se activa y hace que esta "se emplume" a partir de la belleza sensible presente en el cuerpo del amado, el cual funciona como el disparador más obvio y accesible, debido al tremendo impacto de la percepción visual de lo bello (250d). Pese a esto es innegable que el amor filosófico requiere que el caballo negro sea sometido en su desenfreno y frustrado en su apetencia sexual para que la parte racional logre el dominio y armonía de toda el alma y pueda perseguir sus anhelos ético-epistémicos, es decir fortalezca y despliegue las alas del deseo que se nutren de la contemplación de la verdadera realidad. Pero ¿cómo entender entonces la afirmación en $246 \mathrm{~d}$-e de que el ala es "de todo lo vinculado con el cuerpo, la que mayor participación tiene con lo divino" y la descripción del alma como "toda alada" (251b; cf. también 246a), no únicamente su parte racional? Pareciera entonces que el erōs físico no solo habilita el surgimiento sino que, de algún modo, precisamente la renuncia a sus ardientes

\footnotetext{
${ }^{34}$ La almas que guardan algún recuerdo de la visión plena de la realidad eidética "quedan fuera de sí" (ekplēttontai) al ver sus símiles sensibles, pero no saben qué les pasa "por no percibir de modo cabal" (dia to mē hikanōs diaisthanethai). 250a.
} 
apetencias carnales acicatea el amor metafísico: en esto consiste el juego de "someter lo malo" y, a la vez, "liberar lo bueno". ${ }^{35}$ Si estas se consumaran y el amante creyera alcanzar su objeto de amor a través de la posesión física del bello amado, evidentemente las alas del deseo no crecerían y las plumas en corto tiempo se marchitarían, como en el caso del casquivano amante del Discurso lisíaco. En cambio, al sustraer el objeto de deseo a través de reconocer que en el bello amado está presente la belleza en sí pero no es lo bello en sí, erōs puede extenderse a otros ámbitos, encontrar su verdadero origen -la belleza pura- y nutrirse de ella. ${ }^{36}$ Las limitaciones de la estructura psíquica del alma humana -el caballo negro no puede suprimirse-, con su apego a lo somático, harán que sus alas nunca puedan alimentarse exclusivamente de la llanura de la verdad, como en el caso de las de los dioses; a su vez, la atracción física por la hermosura del bello amado funcionará, por otra parte, como permanente incentivo en tanto se lo mantenga como representante de un plano ideal inalcanzable. Así puede explicarse que las alas se vinculen al cuerpo y, además, participen de lo divino; también que toda ella sea alada pues, en caso de una reorganización ideal de las fuentes motivacionales del alma, la fuerza toda de erōs se encauzaría firmemente hacia la realidad eidética. El extraño modo en que el erōs físico se convierte en incentivo del amor por la verdad se refleja también en los sentimientos mezclados de incomodidad, estupor y extrañeza que experimenta el afectado por la locura erótica divina (251d-e). Por otra parte, este "amor platónico" a nivel interpersonal sería a su vez el más duradero: al negarse a su concreción física el bello amado conservaría su idealidad y seguiría operando como fuerza motivacional, tanto para el amante como para sí mismo, al instanciar y al mismo tiempo no poder ser reducido a la belleza en sí. No obstante, es probable que, con el transcurso de los años,

${ }^{35}$ Podemos pensar que, así como los poetas mélicos encuentran en el amor no correspondido el gran motor para expresarse en verso (Calame,2002, p. 41), de igual modo Platón descubre que al vetar la concreción física potencia la expresión filosófica de erōs. Poratti (2010, pp. 310-311) también interpreta que en el amante-filósofo la excitación sexual incita al amor por la verdad y califica por este motivo a la propuesta platónica como perversa.

${ }^{36}$ En forma similar al concepto de sublimación freudiana el erōs bestial transmuta en erōs espiritual; la diferencia fundamental es que para Platón no se trata de transformar nuestras tendencias animales en expresiones más elevadas sino de descubrir el verdadero origen y objeto de nuestro anhelo: lo bello en sí. Vid. Cornford (1974, p. 144). 
se apacigüe el ímpetu de la pasión física al tiempo que crece la comprensión y el amor por la belleza en sí, transformándose entonces en un sentimiento de philía hacia al amado (256c-d).

iv. Sōphrosynē, amor y conocimiento. En lo que se refiere a la sōphrosynē vimos que en los dos primeros discursos es presentada como la virtud de la "moderación" -es decir, la perfección del autocontrol- y a su vez como el "sano juicio", una opinión que aspira a lo mejor en oposición a las apetencias desmesuradas del erōs carnal. En el caso del Segundo Discurso de Sócrates el elemento epistémico en un sentido fuerte parece, en principio, ser determinante. Si bien la rememoración de la auténtica sōphrosynē, junto con otras virtudes morales, no es tan intensa como la de la belleza (250a), en contraste con la visión directa y plena de todas ellas que tienen los dioses (247d), es al recordarla junto con lo bello en sí que la razón retrocede y no claudica a las exigencias de los apetitos. Leemos así en 254c:

Pero, cuando el disturbio no tiene fin, [el auriga y el caballo blanco] terminan por dejarse llevar, sucumbiendo y accediendo a hacer lo requerido [por el caballo negro]. Entonces llegan cerca del muchachito y ven su rostro deslumbrante. Y, al contemplarlo el auriga, su memoria se transporta a la naturaleza de la belleza y la ve nuevamente junto con la sōphrosynē establecida en un pedestal sagrado. Al ver esto, se estremece de temor y, al sentir veneración, retrocede.

A la luz de la caracterización de la sōphrosynē en República (442c-d) podríamos suponer que a nivel psíquico $-y$, por extensión, también político (431a-432a), según el principio de homología estructural entre ciudad e individuo- esta consiste en la armonía entre las partes del alma y en el acuerdo entre ellas de que lo superior (la razón) domine sobre lo inferior (los apetitos). Ahora bien, este pasaje del Fedro no implicaría simplemente que un estado epistémico óptimo -la captación cabal de la esencia de la sōphrosynē en sí- provoque en automático un perfecto autodominio de las motivaciones sino que, al nutrirse y fortalecerse el anhelo por la verdad -las alas del deseo- de la parte racional, especialmente a partir de la rememoración de la Forma de la belleza a partir de la visión del bello muchachito, la razón, además de comprender el fundamento último de por qué ejercer el control (Griswold, 1986, pp. 
132-133), consolidaría su propia fuerza motivacional. Sería entonces que se alcanzaría la auténtica virtud de la sōphrosynē tanto en el sentido de "moderación" como de "sano juicio".

\section{La mania erótica divina como experiencia metafísica: razón intuitiva y razón dialéctico-discursiva; tipos de anamnēsis}

En el contexto mítico del carro alado del Fedro el acceso a las Formas en nuestro modo de existencia actual, esto es la de un alma encarnada en un cuerpo, se explica en términos de anamnēsis, es decir como un "rememorar" de un conocimiento previo y más pleno de la realidad eidética, bajo el supuesto -como ocurre en contextos míticos similares en Menón y en Fedón con este tipo de explicación- de la inmortalidad del alma y su periplo transmigratorio. Esta reminiscencia se da en el Fedro bajo tres modalidades, en las que interviene de distinto modo la locura erótica divina.

R1. En línea con la interpretación IM, en el recién iniciado, el amante filósofo, a causa de la percepción de la belleza física del amado y la pasión amorosa que esta desata, se activa el recuerdo de la contemplación directa de la belleza en sí.

Pero en lo que respecta a la belleza, como dijimos, esta resplandecía entre las otras realidades y, tras volver a aquí, la hemos captado con extrema nitidez en su fulgor a través de la más palmaria de nuestras sensaciones [...Ú]nicamente la belleza ha tenido esta suerte de ser manifiesta y atrayente de modo superlativo.37 Así pues, quien no se inició o ha sido corrompido no es transportado rápidamente de aquí hacia allí, hacia la belleza en sí, al contemplar su homónimo acá. ${ }^{38}$ En cambio, ${ }^{39}$ el recién iniciado, quien

\footnotetext{
${ }^{37}$ Como ya señalamos en la sección anterior, el obvio atractivo de la Forma de la belleza y su inmediato impacto a través de la vista la convierte en un catalizador poderoso y privilegiado del erōs.

${ }^{38}$ Queda en evidencia aquí que las Formas, como es aquí el caso de la belleza, es fundamento ontológico -lo que hace bellas a las cosas bellas-, gnoseológico -lo que permite comprender por qué las cosas bellas son bellas- y, a su vez, lingüístico -lo que nos permite denominar correctamente a las cosas bellas como tales.

${ }^{39}$ En esta fenomenología del enamoramiento se proporciona una descripción pormenorizada de lo que experimenta aquel que se enamora, al tiempo que se procura dar cuenta de aquello que lo causa, en último término la Forma de la belleza presente en una "buena copia" en la personas bella que se desea. Si nos remitimos a la teoría de la mimēsis de R.10.597a, las personas hermosas serían "buenas
} 
contempló multiplicidad de cosas en aquel entonces, cada vez que ve un rostro divino o una figura corporal que imita bien la belleza, al principio se estremece y algo de sus antiguas conmociones lo asalta. ${ }^{40}$

En tal sentido el enamoramiento se transforma para el amante en una experiencia metafísica en la que se capta y vivencia una dimensión eterna y absoluta la Forma de la belleza- a través del amor por alguien en particular. Tiene lugar así la modalidad noético-intuitiva de la razón, si bien de modo sesgado, ya que solo se daría plenamente en una existencia sin las limitaciones del cuerpo mortal y con una configuración psíquica similar a la de los dioses. ${ }^{41}$ Se afirma así en $250 \mathrm{~b}$-c:

Pero en aquel tiempo la belleza era esplendorosa a la vista, cuando, junto con el coro feliz -nosotros, a la zaga de Zeus, otros, de algún otro de los dioses- vimos una visión y un espectáculo dichosos. Entonces éramos instruidos entre los misterios en aquel que es justo llamar el más dichoso, el cual celebrábamos siendo íntegramente nosotros mismos y sin padecer los males que nos aguardaban posteriormente. Todo ello por estar iniciados en revelaciones íntegras, absolutas, inconmovibles y felices, alcanzar la iniciación final en la pura luminosidad, ser puros y no estar sepultados en esto que ahora llevamos alrededor y llamamos "cuerpo", encadenados a él al modo de una ostra. $^{42}$

copias" por ser "copias de primer orden", tal como el resto de la belleza natural, que no es producida por el ser humano sino por el Hacedor del universo.

${ }^{40}$ Aquí vemos que el cuerpo mortal, aunque por una parte puede ser una prisión, por el otro, ocupa un lugar privilegiado como disparador del proceso de anamnēsis en relación con la Forma de la belleza. Esto se corresponde con el comienzo del ascenso amoroso por los cuerpos bellos en Smp. 210a.

${ }^{41}$ Solo la mente del dios, poseedora de un intelecto y conocimiento sin mezcla, ve lo real y se nutre regularmente y sin impedimentos de la contemplación de las cosas verdaderas. El resto de las almas, en cambio, aun aquellas que mejor imitan al dios, alcanzan apenas una visión parcial y esforzada de lo que es y, aturdidas, ingresan a una existencia somatizada (cf. 247e-248a). Vid. Steinthal (1993, pp. 99-105).

${ }^{42}$ La comparación del sōma mortal con la valva de una ostra que veda el acceso a la auténtica esencia del alma ocurre también en R.10.611c-612a. Allí, asimismo, se establece un símil con el dios marino Glauco, cuya verdadera naturaleza permanece oculta por los estragos y adherencias que han ocasionado su convivencia con el tumultuoso mar. En el Fedro, esta concepción del cuerpo como empodion ("obstáculo") se complementa con la de un cuerpo que puede transformarse, como en el caso de los dioses, en un ochēma ("vehículo") de la actividad inteligente del alma. 
El enamoramiento es entonces equiparable con una experiencia mística, en la medida en que hay contacto con un plano divino y eterno, el de las Formas, especialmente la de la belleza. La maravilla del amor es que el enamorado registra que, a través de una pasión terrenal y frágil, accede a la certeza de algo inmortal y trascendente. Su descripción como un conocimiento "dado" bajo la forma de un estado alterado de consciencia permite a Platón, asimismo, dar cuenta de otra cuestión: la intervención de un aditamento de orden misterioso sin el cual el más acabado ejercicio de cualquier técnica jamás alcanzaría su perfección.

R2. En segundo término también aparece planteada la anamnēsis como el conocimiento del alma en una existencia anterior, en mayor o menor medida, del entramado eidético de la realidad. En efecto la marca distintiva del alma-no divina que puede llegar a adoptar una existencia humana es la de su capacidad de organizar la multiplicidad sensible de acuerdo a conceptos universales. En esto la forma de operar de la razón humana es similar a las categorías a priori de Kant de acuerdo a las cuales, junto con las intuiciones puras del espacio y el tiempo, se esquematiza la multiplicidad de la experiencia. El énfasis de la filosofía platónica se encuentra, no obstante, en el proceso de anamnēsis a través del cual somos capaces "recordar", es decir, de reconocer activa y reflexivamente esta organización eidética de la realidad y avivar así el crecimiento de las "alas" del erōs por la verdad (vid. Scott, 1987, pp. 346-366). Y solo unos pocos, los filósofos, pueden dar cuenta de esta conceptualización de la experiencia empírica, es decir comprender lo que cada cosa realmente es -la Forma- y explicitar esa comprensión en el lenguaje. Leemos así en 249c:

Ya que un ser humano necesariamente comprende lo que se dice de acuerdo con la Forma (kat'eidos), ${ }^{43}$ al partir de múltiples sensaciones y agruparlas en una unidad a través del razonamiento (logismōî). Y en esto consiste la reminiscencia de aquellas cosas que nuestra alma una vez vio cuando, al viajar en compañía del dios y desdeñar

${ }^{43}$ La palabra griega idea ("forma") es, junto con eidos, la que utiliza Platón para referirse a las Formas metafísicas, como ocurre aquí, si bien puede usarla también de modo más amplio para referirse a los rasgos que comparten agrupamientos de todo tipo de entidades. Cf. 237e y 265c. 
las cosas que ahora decimos que son, asomó su cabeza hacia la verdadera realidad. Por ello es justo que únicamente la mente del filósofo adquiera alas. Pues, gracias a la memoria, su mente está, en la medida de lo posible, siempre junto a aquellas cosas por proximidad a las cuales el dios es divino. ${ }^{44}$

Este conocimiento previo consiste aquí, de modo similar al concepto de "dialéctica" que se propone en la Segunda Parte, en el entrelazamiento de géneros y especies que nos permiten lo que podríamos denominar una comprensión prereflexiva de la cartografía de lo real. Ello sugiere, en coincidencia con la interpretación RDD, que el método dialéctico (266a-c), ya sea en su forma más específica de unión y división o más amplia de pensar y hablar correctamente, apunta justamente a recuperar -"recordar"- una comprensión reflexiva lo más acabada posible y, en último término, a intentar transparentar el entramado eidético que fundamenta y explica la realidad en todas sus manifestaciones. Aquí no hay una captación directa como en IM sino mediada por la palabra y el pensamiento discursivo, por la argumentación. El modo de operar IM de la razón, activado a través de la locura erótica divina, complementa entonces a RDD al proporcionar la certeza de la existencia este plano eidético y complementar la visión sinóptica de la cartografía de lo real que en la indagación discursiva se utiliza como un supuesto y solo se reconstruye en forma parcial. La captación intuitiva de la dimensión eidética incentiva, además, el deseo por la verdad que es indispensable para que la razón pueda realizar el esfuerzo de operar en el modo RDD.

R3. En tercer término en el Fedro se plantea otro tipo de anamnēsis que se produce a través del reconocimiento y recuerdo del dios al que el alma seguía en la caravana en estado desencarnado, al enamorarse de un bello joven que responde a esa misma constitución psíquica. En el caso del amante filósofo reencuentra el amado los rasgos del dios que ha seguido en la procesión de las almas al lugar fuera del cielo -

${ }^{44}$ El desiderátum es entonces del de asemejarnos al dios lo más posible en la medida en que recuperamos el conocimiento de las Formas y operamos de acuerdo a este. Por otra parte, se sugiere aquí que los dioses son divinos por su eficiencia para estar en contacto con las Formas y no viceversa. $C f$. también Euthphr.10a-11a. 
Zeus- al tiempo que intenta deducir cuáles son las "ocupaciones" -epitédeumatacorrespondientes para aplicarlas también al modo de vincularse con su amado. Leemos así en 252d-253a:

Cada uno selecciona el amor por los bellos muchachos 45 de acuerdo con su carácter, y construye en su interior, por así decirlo, una efigie sagrada de su amado y la embellece como si aquel fuera él mismo su dios para honrarlo y celebrarlo. Entonces, los seguidores de Zeus buscan que su amado sea alguien luminoso por su alma. ${ }^{46}$ Así que observan si, en su naturaleza, es filósofo y conductor. ${ }^{47}$ Una vez que lo encuentran y se enamoran, hacen de todo para que llegue a ser alguien de tal índole. Ahora, si no se han involucrado antes en esta pauta de vida, entonces, al emprender la tarea, se instruyen de donde sea que puedan aprender algo y realizan ellos mismos la búsqueda. Al seguir el rastro dentro de sí mismos para descubrir la naturaleza de su dios, hallan los medios apropiados para esto gracias a la febril compulsión por dirigir la mirada al dios. Al captarlo por medio de la memoria y al estar poseídos por el dios, adquieren de este los hábitos y comportamientos, tanto como sea posible para el hombre participar de lo divino. (Mis itálicas)

En tal sentido, el efecto armonizador de las distintas fuentes motivacionales del alma en el caso del filósofo no se da directamente a partir de la contemplación de las Formas que le transmitirían sus características de orden y uniformidad (Seeskin, 1976, p. 583) -si bien la parte racional del alma en su más elevada expresión, el nous, guarda una relación de afinidad con la dimensión eidética (cf. Phaed. 78b-84b)- sino que implicaría que el amante y también el amado, puesto que este último será del mismo tipo psicológico, imiten la configuración psíquica divina correspondiente de Zeus, quien, además de tener bajo control total de los aspectos irracionales de su alma (los caballos), la mueve del modo más inteligente, por un conocimiento pleno de la

${ }^{45}$ Otra posible traducción es "elige su objeto de amor entre los jóvenes bellos", pero tōn kalōn puede interpretarse también como el usual genitivo objetivo que acompaña a erōs (vid. Yunis, 2011: ad loc.).

46 Con "luminoso" (dion) Platón sugiere a su vez que sea similar a Zeus (Dios) y quizá haya también una alusión a Dión, de Siracusa, el amado de Platón (cf. D.L. III.30).

${ }^{47}$ Zeus aparece como conductor del universo (246e). En el plano humano esto implicaría ser filósofo y conductor político, como se plantea en República a propósito del rey filósofo. 
realidad eidética, a la vez que administra todo el universo (representado esto a través del liderazgo de Zeus en la caravana de los dioses hacia la contemplación regular y periódica del lugar fuera del cielo). Los otros dos tipos de anamnēsis contribuirían a consolidar la estructura del alma humana que alcance una configuración similar a la del dios, como es el caso de la del filósofo, en la medida en que, a través del conocimiento y frecuentación de las Formas, se acrecentaría y afianzaría el anhelo de la verdad de la razón al nutrir su expresión noética; así se lograría un control sostenido y cuasi-automático, similar pero no igual, al del alma del dios.

\section{Conclusiones}

Hemos mostrado entonces que para su apología de la locura erótica en el Fedro Platón retoma los rasgos compartidos y diferenciales entre locura ordinaria y locura divina que se establecían desde su contexto cultural. De acuerdo a este, por una parte, en ambos casos la mania refería a una alteración psicosomática del sujeto que se reflejaba en conductas inusuales; por otra parte, la línea demarcatoria en la mania como enfermedad o la mania como intervención divina no siempre era clara, dependía del marco interpretativo y, además, aun cuando considerada de origen divino, no siempre era por eso vista como benéfica, especialmente en el caso de la mania erótica. En tal sentido Platón aprovecha e invierte los valores del contexto cultural respecto a la locura divina, ya que, a partir de añadir a la locura erótica a los subtipos de la locura profética, la catártica y la poética, los cuales eran más respetados como formas de intervención de los dioses, la legitima como de igual procedencia y, a su vez, la convierte en el mejor tipo de las cuatro al revelarla como una vía privilegiada de comprensión del sentido último de la realidad y de mejoramiento personal.

En segundo término hemos tratado cómo, tras desarrollar a través del Discurso lisíaco y del Primer Discurso de Sócrates una supuesta oposición entre razón y locura erótica, a tono con las apreciaciones del sentido común, se ofrece en el Segundo Discurso de Sócrates una propuesta superadora. En efecto en él la locura amorosa ordinaria y la divina coinciden en remitir al mismo estado psicofísico en el amante -el 
apetito sexual exacerbado del amante al descubrir los atractivos del hermoso joven-; también, en conmocionarlo al punto de generar similares conductas extravagantes e insensatas para los más. La diferencia reside en la interpretación que el amante logre hacer de su sorprendente condición: si solo logra apreciar la belleza sensible y apetece saciarse a través de la consumación y un disfrute sin límites de los encantos físicos del amado, se trata solo de una mania erótica ordinaria; en cambio, si el impacto de la hermosura del amado dispara en el enamorado el "recuerdo" de un sentido y anhelo de trascendencia, se resignifica entonces en mania erótica divina. El erōs físico, junto con el resto de los apetitos, resulta entonces un aspecto inextirpable de nuestra alma, que estimula y potencia el deseo metafísico de la razón, si bien precisamente a través de su renuncia a la concreción de sus apetencias. De este modo la razón se convierte en la expresión más elevada y poderosa de la locura erótica por la belleza, al promover una captación directa, si bien sesgada, del entramado eidético y motivar y complementar la investigación reflexiva a través de la dialéctica.

Finalmente analizamos cómo ambas modalidades de la razón son explicadas en el contexto del mito del carro alado como formas de anamnēsis de la dimensión eidética: en el primer caso, de la experiencia de la visión directa de la Belleza pura (R1); en el segundo caso, como reconstrucción del entramado de lo real, que en la Segunda Parte se formula en términos del método de unión y división (R2). Un tercer tipo de reminiscencia (R3) es la de descubrir el patrón de configuración psíquica divina al que corresponde nuestra alma humana, descrito en términos de recordar al dios que seguíamos en la caravana divina. En el caso de las almas filosóficas de estructura "tipo Zeus", a nivel individual imitarían el predominio de los anhelos de la razón por sobre los aspectos motivacionales irracionales. Para ello la creciente vigorización del deseo por la verdad de la razón -el fortalecimiento y expansión de las alas-, a través de R1 y de $\mathbf{R 2}$, contribuirían a estabilizar esta configuración psíquica y al logro de un control sostenido y cuasi-automático de los aspectos irracionales, especialmente de las apetencias sin límite de los apetitos en general y del desenfreno sexual en particular. Pero con la salvedad de que, incluso el propio Zeus, antes de ser el comandante en jefe de las almas divinas y humanas, de acuerdo a la tradición mítica aludida en 255c, 
Amores locos. A propósito de la mania erótica en el Fedro

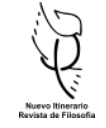

habría enloquecido de tal manera de amor por el bello Ganímedes que lo habría raptado, si bien para otorgarle finalmente la inmortalidad junto a los dioses.

\section{Bibliografía}

1. Ahonen, M. (2014). Mental Disorders in Ancient Philosophy. New York: Springer.

2. Bioy Casares, A. (2015). La invención de Morel. Buenos Aires: Emecé.

3. Bluck, R.S. (1958). "The Phaedrus and Reincarnation", The American Journal of Philology 79.2, 156-164.

4. Burkert, W. (1972). Lore and Science in Ancient Pythagoreanism, tr. E. L. Minar Jr.. Cambridge: Harvard University Press.

5. Burnet, J. (1899-1907). Platonis opera: recognovit brevique adnotatione critica instruxit. Oxford: Oxford University Press.

6. Calame C. (2002). Eros en la antigua Grecia, tr. E. Pérez Rodríguez. Madrid: Akal.

7. Cornford, F. M. (1950). "The Doctrine of Eros in Plato's Symposium", en The Unwritten Philosophy and Other Essays. Cambridge: Cambridge University Press, 68-81.

8. Chantraine, P. (1968). Dictionnaire étymologique de la langue Grecque. Histoire des mots, I-IV. París: Klincksieck.

9. Diolaiti, E. (2017). "Práxis platónica: el dispositivo teatral de los diálogos filosóficos", M.A. Fierro\& C. Valenzuela Issac (eds.) "Retoños de Eros. Grafías y cinematografías platónicas". Aesthethika. Revista Internacional de Estudio e Investigación interdisciplinaria sobre subjetividad, política y arte, v.13, 33-38.

10. Dixsaut, M. (2001). Les metamorphoses de la dialectique dans les dialogues de Platon. Paris: Vrin.

11. Dodds, E.R. (1980). Los griegos y lo irracional, tr. María Araujo. Madrid: Alianza.

12. Fierro, M.A. (en prensa). Platón. Fedro. Buenos Aires: Colihue.

13. Flacelière, R. (1965). Adivinos y oráculos griegos, tr. N. Míguez. Buenos Aires: Eudeba. 
14. Griswold, C. L., (1989). Self-Knowlege in Plato's Phaedrus.New Haven: Yale University Press.

15. Hackforth, R. (1952). Plato's Phaedrus. Cambridge: Cambridge University Press.

16. Halperin, D. M. (1986). "Plato and Erotic Reciprocity", Classical Antiquity 5, 6080.

17. Kazantzakis, N. (1959). Zorba the Greek, tr. C. Wildman. London: Faber and Faber.

18. Liddell, G.-Scott, R.-Stuart-Jones, H (1940, $9^{\text {th }}$ ed.). A Greek English Lexicon. Oxford: Oxford University Press.

19. Lozano Nembrot, M. (2016). Amores en pugna: desarrollos y tensiones de la concepción de éros en Esquines y Platón, Controvérsia II.1, 30-36.

20. McGibbon, D. (1968). The Fall of the Soul in Plato's Phaedrus, CQ 14.1, 56-63.

21. Mc Neill, D. (2001). Human Discourse, Eros, and Madness in Plato's Republic, The Review of Metaphysics, 55, 2, 235-268.

22. Morris, M. (2006). Akrasia in the Protagoras and the Republic, Phronesis, 195229.

23. Naddaf, G. (2009). Algunas reflexiones sobre la noción griega temprana de inspiración poética, Areté. Revista de Filosofía 21.1, 51-86.

24. Nussbaum, M. (1986). The Fragility of Goodness: luck and ethics in Greek tragedy and philosophy. Cambridge: University of Chicago.

25. Poratti, A. (2010). Platón. Fedro. Madrid: Akal.

26. Price, A.W., (1992). Reason's New Role in the Phaedrus. En: L. Rossetti (ed.), Understanding the Phaedrus. Sank Agustin, Akademia Verlag, 243-5.

27. Robinson, R. (1953). Plato's Earlier Dialectic. Oxford: Clarendon Press.

28. Rowe, C. J. (2007). Plato and the art of philosophical writing. Cambridge: Cambridge University Press.

29. Rowe, C.J. (1990). Philosophy, love and madness. En C. Gill (ed.), The Person and the Human Mind. Oxford. Clarendon Press: Oxford, 227-246.

30. Rowe, C.J. (2000). Plato. Phaedrus. Warminster: Aris \& Phillips. 
31. Rowe, C.J. (1986). The Argument and Structure of Plato's Phaedrus, Proceedings of the Cambridge Philological Society 32, 106-25.

32. Ryan, P. (2012). Plato's Phaedrus: A Commentary for Greek Readers. Norman: University of Oklahoma.

33. Scott, D., (1987). Platonic Anamnesis Revisited, Classical Quaterly, vol. 37, no.2, 346-366.

34. Seeskin, K. (1976). Platonism, Mysticism, and madness, The Monist, Vol. 59, No. $4,574-586$

35. Segvic, H. (2000). No One Errs Willingly. The Meaning of Socratic Intellectualism, Oxford Stud. in Anc. Philosophy, 19, 1-45.

36. Steinthal, H., (1993). Mógis und exaíphnes: Platon über die Grenzen des Erkennens. En: Festschrift für W. Heilman zum 65. Geburstag, 99-105.

37. Vlastos, G. (1981). The Individual as an Object of Love, app. II: Sex in Platonic Love. En: Platonic Studies. Princeton: Princeton University Press, 3-42.

38. Von Der Walde, G. (2010). Poesía y mentira: La crítica de Platón a las poéticas de Homero, Hesíodo y Píndaro en el lón y en República 2. Bogotá: Universidad de los Andes.

39. Yunis, H. (2011). Platonos Phaidros. Cambridge: Cambridge University Press. 